\title{
Trace Detection of Pentaerythritol Tetranitrate Using Electrochemical Gas Sensors
}

\author{
Praveen K. Sekhar, ${ }^{1}$ Jie Zhou, ${ }^{1}$ Hui Wang, ${ }^{2}$ and Eric R. Hamblin' \\ ${ }^{1}$ Nanomaterials and Sensor Laboratory, School of Engineering and Computer Science, Washington State University Vancouver, \\ 14204 NE Salmon Creek Avenue, Vancouver, WA 98686, USA \\ ${ }^{2}$ Department of Industrial and Manufacturing Engineering, College of Engineering, Florida State University, \\ 2525 Pottsdamer Street, Building A, Suite A231, Tallahassee, FL 32310-6046, USA
}

Correspondence should be addressed to Praveen K. Sekhar; praveen.sekhar@vancouver.wsu.edu

Received 12 October 2014; Revised 3 December 2014; Accepted 7 December 2014; Published 22 December 2014

Academic Editor: Banshi D. Gupta

Copyright (C) 2014 Praveen K. Sekhar et al. This is an open access article distributed under the Creative Commons Attribution License, which permits unrestricted use, distribution, and reproduction in any medium, provided the original work is properly cited.

\begin{abstract}
Selective and sensitive detection of trace amounts of pentaerythritol tetranitrate (PETN) is demonstrated. The screening system is based on a sampling/concentrator front end and electrochemical potentiometric gas sensor as the detector. A single sensor is operated in the dominant hydrocarbon $(\mathrm{HC})$ and nitrogen oxides $\left(\mathrm{NO}_{x}\right)$ mode by varying the sensor operating condition. The potentiometric sensor with integrated heaters was used to capture the signature of PETN. Quantitative measurements based on hydrocarbon and nitrogen oxide sensor responses indicated that the detector sensitivity scaled proportionally with the mass of the explosives $\left(10 \mu \mathrm{g}\right.$ down to $200 \mathrm{ng}$ ). The ratio of the $\mathrm{HC}$ integrated peak area to the $\mathrm{NO}_{x}$ integrated peak area is identified as an indicator of selectivity. The $\mathrm{HC} / \mathrm{NO}_{x}$ ratio is unique for PETN and has a range from 1.7 to 2.7. This detection technique has the potential to become an orthogonal technique to the existing explosive screening technologies for reducing the number of false positives/false negatives in a cost-effective manner.
\end{abstract}

\section{Introduction}

The 2011 Department of Homeland Security (DHS) Progress Report [1] on "Implementing 9/11 Committee Recommendations" places important precedence on improving national security through robust explosive screening technologies. Moreover, given the widespread use of explosive formulations, the analysis of explosives is also of interest in landmine detection, forensic research, and studying environmental problems associated with explosive residues. Among the different explosives, nitroaromatics are perhaps the most commonly used and from them PETN is the one with highest shattering capability. Several techniques have been developed to detect TNT including fluorescence [2], Raman spectroscopy [3], mass spectrometer [4], ion mobility spectrometry [5], metal oxide gas sensors [6,7], and electrochemical sensing [8].

The detector combination of gas chromatography (GC) and mass spectrometry (MS) is currently considered a gold standard [9] for explosives detection. However, the high cost of GC-MS, their bulky size, and the need for an informed end user have motivated investigations for new screening technologies, which are more cost effective [10]. Among the several modalities to screen explosives, electrochemical detection possesses several advantages such as easy operation, low cost, high sensitivity, simple instrumentation, suitability for portable devices, and, depending on the nature of the technology, the potential for extended shelf life and minimal calibration requirements [11-13]. The drawback of electrochemical devices is the poor sensitivity in detecting explosives vapor, as the vapor pressure of most explosives is extremely low. Another drawback is the general lack of ability to discriminate or identify the detected explosive. However, while the presence of a preconcentrator has been demonstrated as a way to ameliorate the first barrier, the electrochemical sensing of explosives reported to date typically relies on the detection of redox potentials, especially the redox potential of $\mathrm{NO} / \mathrm{NO}_{2}$ and therefore discrimination 
of the high explosive ( $\mathrm{HE}$ ) species particularly in a complex background with many chemical signatures becomes unlikely.

Probing the vapor phase (instead of solid or liquid) surrounding the potential threat may lead to improved means for threat detection. The inevitable gas phase decomposition of explosives that are made up of $\mathrm{C}, \mathrm{H}, \mathrm{N}$, and $\mathrm{O}$ involves highly predictable and readily measurable principal "breakdown" components such as $\mathrm{NO}, \mathrm{NO}_{2}, \mathrm{CO}, \mathrm{CO}_{2}$, $\mathrm{C}_{3} \mathrm{H}_{6}, \mathrm{NH}_{2}$, and $\mathrm{NH}_{3}$ [14]. By detecting the breakdown components, the signature of the explosives can be obtained. In this context, electrochemical gas sensors can be used to screen the explosives. Among the several classifications of electrochemical gas sensors, mixed potential based devices have gained prominence in gas sensing applications.

Mixed potential sensors are a class of electrochemical devices, which develop a non-Nernstian electromotive force (EMF) due to the difference in the kinetics of the redox reactions at each electrode/electrolyte interface upon exposure to various analytes [15-17].

These sensors rely on the fact that two dissimilar electrodes along with an oxygen ion conducting electrolyte exhibit different nonequilibrium potentials in the presence of a reducing gas and oxygen. The mixed potential based sensing mechanism facilitates sensor miniaturization and a direct voltage read-out circumventing the need for any additional conditioning circuitry. The mixed potential strongly depends on the catalytic and electrocatalytic properties near the threephase interface (electrode/electrolyte/gas), which in turn depend on the operating temperature of the sensor.

In an earlier study by the authors [18], detection and discrimination of explosives such as PETN, TNT, and RDX were demonstrated using tape-cast ceramic mixed potential sensors based on a zirconia solid electrolyte. The nature of the oxygen ion conducting solid electrolyte required that these devices be operated above $450^{\circ} \mathrm{C}$ to function. In that work, the tape-cast hydrocarbon $(\mathrm{HC})$ and nitrogen oxides $\left(\mathrm{NO}_{x}\right)$ sensors were externally heated in a miniature tube furnace with preconcentrator as the front end. The sensitivity and the detection limit were found too low. The detection limit was around $1 \mu \mathrm{g}$. The diminished sensitivity and selectivity were attributed to external heating of the sensors and the subsequent high temperature decomposition of explosive before reaching the sensor surface (thereby limiting the amount of analyte reaching the three-phase interface of the sensor) for electrochemical detection.

Hence, in an attempt to understand factors dictating the limits of detection using mixed potential type electrochemical sensors, a change in sensor design was adopted. Instead of external heating in a furnace, a commercial high temperature ceramic cofire (HTCC) approach was used to prepare sensors with platinum heaters integrated into a planar device structure. Due to this modification, a different sensor package configuration was used from previous work with the front end remaining the same. Reiterating, the difference between this paper and the earlier work is the integrated heater sensor structure as opposed to heating the sensors externally in a tube furnace. The front end houses a state-of-the-art preconcentrator system [19] (a hand-portable sample collection and preconcentrator device), which, when combined with an appropriate method of detection, is capable of detecting vanishingly faint odors (parts per trillion) of explosives, drugs, and other chemicals. In this study, preferential $\mathrm{HC}$ and $\mathrm{NO}_{x}$ mixed potential sensors were used in tandem with integrated heaters with a view to improve the sensitivity and detection limit. PETN was used as the analyte.

\section{Experimental}

The sensor setup for explosives detection is shown in Figure 1. The planar sensor was mounted into custom made Macor sensor holder with compression contact of four Pt-leads, two leads for making electrical connection to the electrodes and two leads connecting the integrated Pt heater to the power supply board. The assembly was placed into a specially prepared quartz tube with a sealed end that placed the sensor electrodes in the test gas stream. An O-ring around the Macor fixture was used to hold the apparatus in place and seal the gas environment.

In this "cold-wall" setup, the Pt heater is the only source of heat supplied to the sensor components. A single sensor was used to measure both $\mathrm{HC}$ and $\mathrm{NO}_{x}$ gas species exploiting unique properties of this sensor construct [20] under different operating conditions. The $\mathrm{HC}$ and $\mathrm{NO}_{x}$ stick sensor was made of screen-printed Sr-doped lanthanum chromite as the working electrode and screen-printed $\mathrm{Pt}$ as the pseudoreference and/or counter electrode. The heater pattern was designed to obtain the required heater resistance utilizing a standard Pt heater ink composition. The details of the sensor fabrication can be found in an earlier article [20]. The sensor inside the housing was tuned for preferential $\mathrm{NO}_{x}$ response by the appropriate application of a current bias [21] and the appropriate choice of the sensor operating temperature. Selective HC response was obtained under open-circuit conditions and appropriate selection of the sensor operating temperature. A current bias of $0.3 \mu \mathrm{A}$ was applied to obtain the $\mathrm{NO}_{x}$ response. A constant resistance power supply (Model 1450-H, Custom Sensor Solutions, Inc.) board was used to precisely control the operating temperature of the sensor. In the $\mathrm{NO}_{x}$ operating mode, the sensor was maintained at $500^{\circ} \mathrm{C}$ while the sensor was maintained at $475^{\circ} \mathrm{C}$ for the $\mathrm{HC}$ operating mode. The sensor response in $\mathrm{HC}$ and $\mathrm{NO}_{x}$ mode is shown in Figures 2 and 3, respectively. The sensor leads were connected to the 2400 Keithley source meters to monitor the $\mathrm{HC}$ and $\mathrm{NO}_{x}$ response while the temperature of the surface in contact with the HE samples was recorded through another 2400 Keithley source meter via a Fluke $80 \mathrm{TK}$ thermocouple module.

Trace samples of PETN were obtained using Accustandards (high purity analytical calibration standards typically used to calibrate IMS and gas chromatography/mass spectroscopy (GC/MS) analytical instrumentation). The total volume of the samples procured was $1 \mathrm{~mL}$. PETN $(99.8 \mu \mathrm{g} / \mathrm{mL}$, balance methanol) formed the de minimis quantities of explosives. The HE/methanol sample was transferred directly onto the felt using a small hot-wire device. Using this latter approach, the $\mathrm{HE} /$ solvent mixture was placed onto a small resistive wire. Then after evaporation of the liquid 


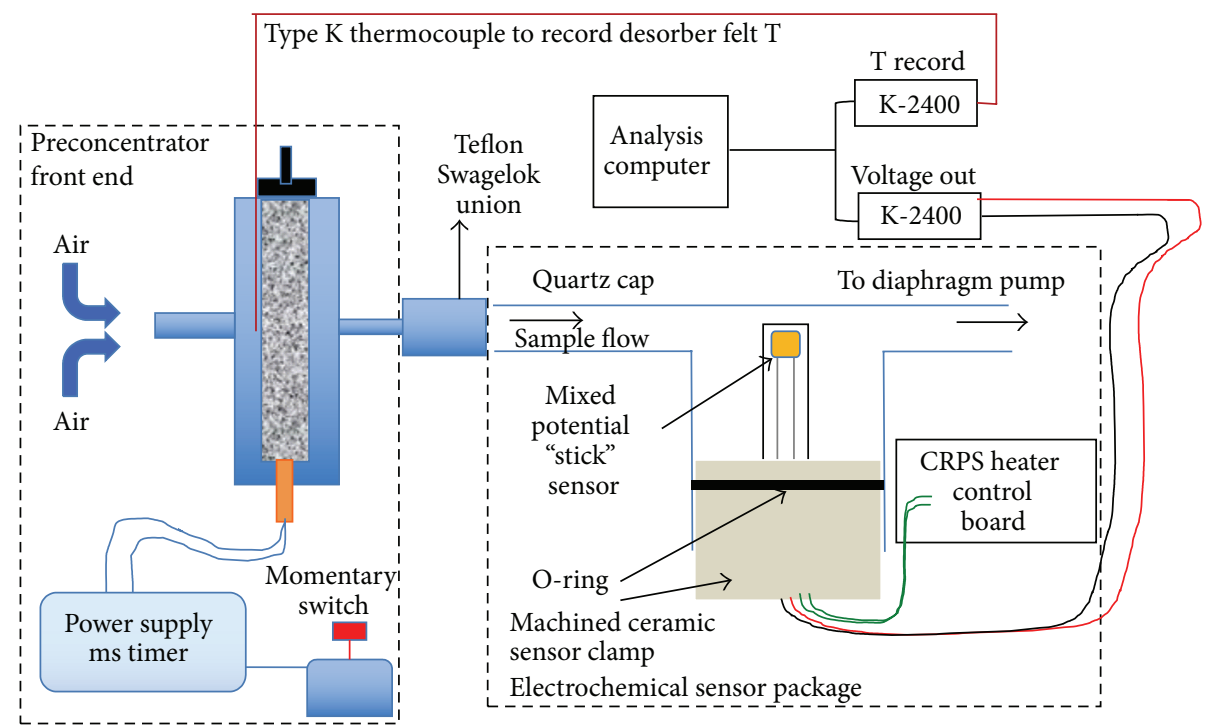

FIGURE 1: Experimental schematic showing the explosives detection setup.

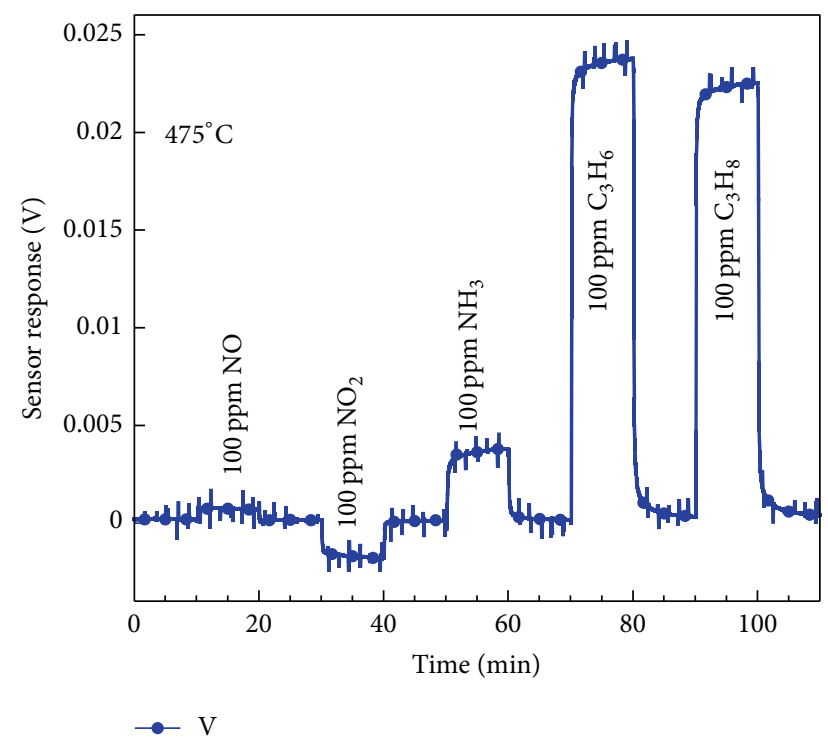

FIgURE 2: Selective HC sensor response.

solvent, an electric current was pulsed through the wire ( $\mathrm{msec}$ duration) to rapidly increase the vapor pressure of the sample without decomposing it. A separate sampling unit containing the felt used for sample concentration pulled a stream of room air through the felt using a high-speed motor with impeller. The HE vapor and particulates of HE were subsequently trapped on the surface of the felt [22]. The benefit of using this approach is that complete evaporation of the solvent from the hot wire ensures that the electrochemical sensor detects only a signature from the explosive compound and not from the solvent. The concentrator felt had a thermocouple spot welded to it to permit monitoring of the desorption temperature.

After trapping the HE molecules on the surface of the felt, the collector felt module was rapidly heated with high degree

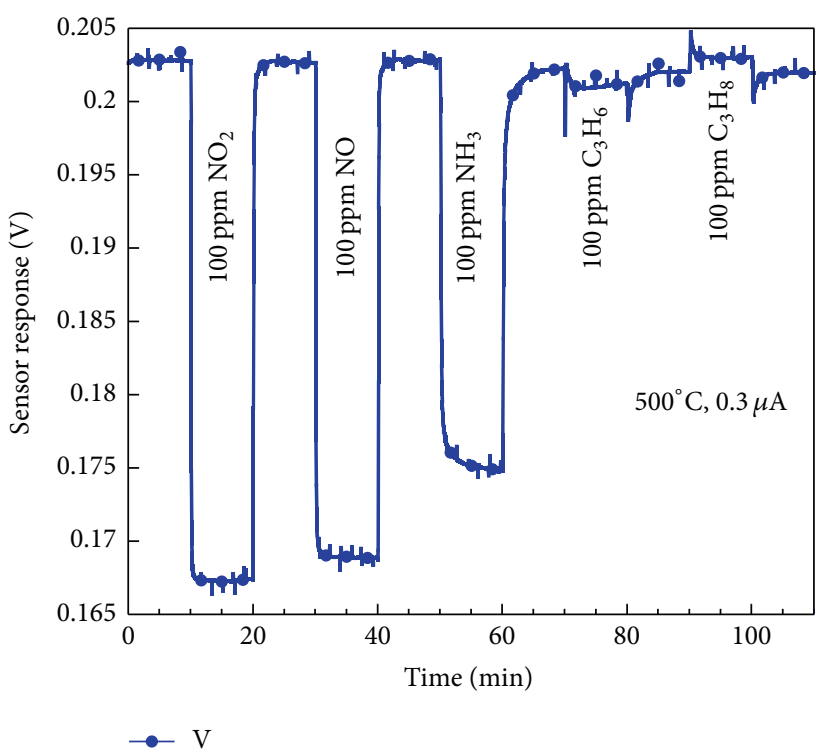

FIGURE 3: Selective $\mathrm{NO}_{x}$ and $\mathrm{NH}_{3}$ sensor response.

of reproducibility $(<0.5 \mathrm{~s})$ to the desired set-point temperature $\left(160^{\circ} \mathrm{C}\right)$ in airflow $(300 \mathrm{~mL} / \mathrm{min})$. The rapid heating of the collector felt results in the release of HE molecules from the felt surface (they were adsorbed to) directly to the mixed potential gas sensors operating downstream in a glass fixture. First, the background signal in the absence of explosives vapor was collected for both the sensors by flashing the felt without the trace explosives adsorbed on them. Further, the concentrations of the explosives were varied $(10 \mu \mathrm{g}$ down to $200 \mathrm{ng}$ ) to observe the sensor response. The area under the peak for the $\mathrm{HC}$ and $\mathrm{NO}_{x}$ sensor is an indicator of the device sensitivity. On the other hand, the ratio of the area under the peak of $\mathrm{HC}$ and $\mathrm{NO}_{x}$ sensor response is an indicator for selectivity. 


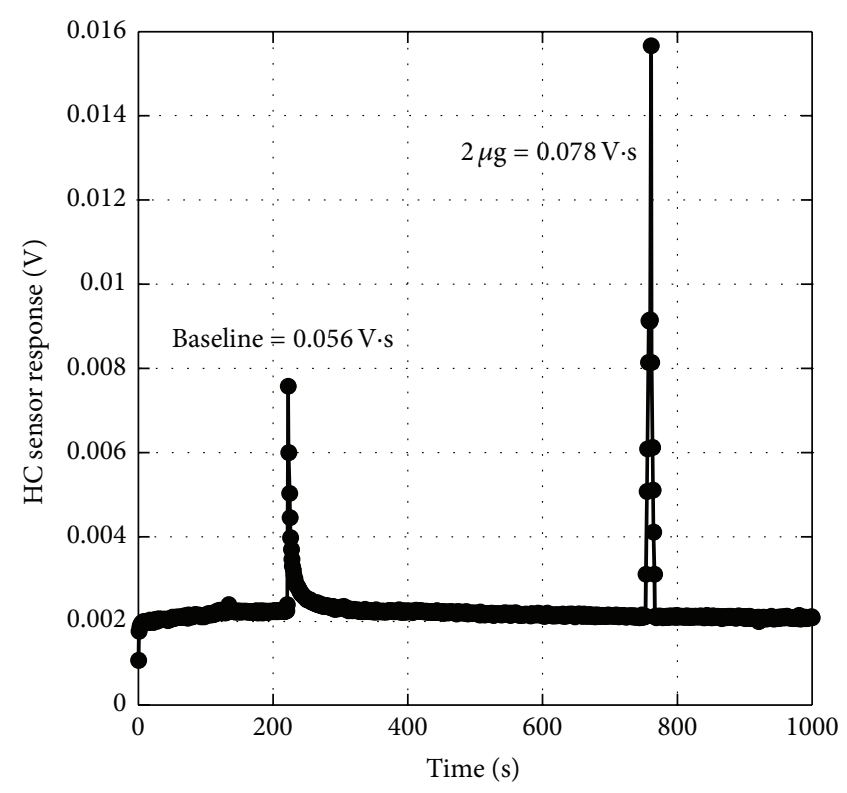

(a)

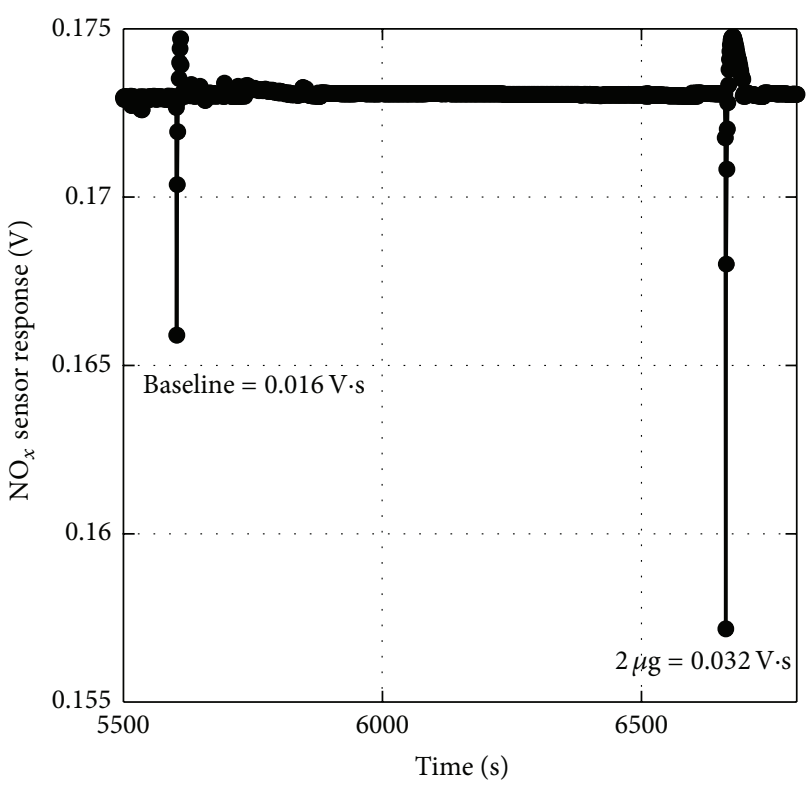

(b)

FIgURE 4: Baseline responses of the sensor upon flashing the empty felt. (a) HC mode and (b) $\mathrm{NO}_{x}$ mode.

\section{Results and Discussion}

Figures 4(a) and 4(b) show the baseline responses of the $\mathrm{HC}$ and $\mathrm{NO}_{x}$ sensor upon flashing the empty or clean felt, respectively. It is ensured that the clean felt is devoid of any explosives or solvent. Ideally, there should have been no peaks after flashing the empty felt. But the $\mathrm{HC}$ and $\mathrm{NO}_{x}$ sensor responses deviated from their sensor baselines with sharp peaks. The origin of this baseline peak response is still under investigation. At this point, the anomalous baseline response is speculated to the outgassing of the polymer insulation on thermocouple wire that was attached to the surface of collector felt; however, this will be rigorously investigated in future work. The area under the peak for the $\mathrm{HC}$ and $\mathrm{NO}_{x}$ baseline response was found to be $0.056 \mathrm{~V} \cdot \mathrm{s}$ and $0.016 \mathrm{~V} \cdot \mathrm{s}$, respectively. Figures $4(\mathrm{a})$ and $4(\mathrm{~b})$ also show the $\mathrm{HC}$ and $\mathrm{NO}_{x}$ response corresponding to $2 \mu \mathrm{g}$ of PETN. The peak height of both $\mathrm{NO}_{x}$ and $\mathrm{HC}$ response corresponding to $2 \mu \mathrm{g}$ was observed to be larger than the baseline.

Figures 5 and 6 show the $\mathrm{HC}$ and $\mathrm{NO}_{x}$ sensor response as a function of PETN concentration, respectively. With an increase in the concentration of PETN, the sensor response seems to increase for both $\mathrm{HC}$ and $\mathrm{NO}_{x}$ sensor. As the baseline response cannot be neglected, it is taken into consideration prior to calculating the sensor peak areas. The data shown in Figures 5 and 6 incorporates baseline correction.

The area under the sensor peaks accounts for the sensitivity. A linear trend was observed for the $\mathrm{HC}$ and $\mathrm{NO}_{x}$ responses upon exposure to different concentrations of PETN. The test was repeated three times and a statistical variation of $1 \%$ in sensor response was observed. This statistical variation in the $\mathrm{HC}$ and $\mathrm{NO}_{x}$ is reflected as error bars. The equation for the linear trend for the $\mathrm{HC}$ response was found to be " $y=0.0091553+0.007356 x$," where $y$ denotes the integrated peak area and $x$ denotes PETN concentration. The goodness of fit was found to be 0.99 . The equation for the linear trend for the $\mathrm{NO}_{x}$ response was found to be " $y=$ $0.011037+0.002028 x$," where $y$ denotes the integrated peak area and $x$ denotes PETN concentration. The goodness of fit was found to be 0.97 . The sensing mechanism to detect PETN can be speculated. Based on the available literature [23], PETN decomposes at $163^{\circ} \mathrm{C}$ into 11 byproducts that include $\mathrm{NO}_{2}, \mathrm{CH}_{2} \mathrm{O}, \mathrm{N}_{2} \mathrm{O}, \mathrm{NO}, \mathrm{CO}_{2}, \mathrm{CO}, \mathrm{H}_{2} \mathrm{O}, \mathrm{CH}_{3} \mathrm{OH}, \mathrm{HNO}_{2}$, $\mathrm{CH}_{3} \mathrm{NO}_{2}$, and $\left(\mathrm{O}_{2} \mathrm{NOCH}_{2}\right)_{3} \mathrm{C}-\mathrm{CHO}$. The mixed potential $\mathrm{HC}$ and $\mathrm{NO}_{x}$ sensor sees a mixture of these byproducts. The sensor response to this mixture is complex and is further convoluted by the catalytic nature of the electrode and the electrolyte. For an accurate understanding of the relationship between the sensitivity and the concentration of the explosives, it is essential to (a) investigate the gas phase decomposition of the explosives at the operating temperature of the sensors, (b) study homogenous (in the system) and heterogeneous catalysis (on the sensor electrodes and electrolyte) as a function of explosives concentration, and (c) study thermodynamics and kinetics of gas phase flow of the explosive vapor over hot surfaces.

To evaluate the selectivity, the ratio of the $\mathrm{HC}$ sensor peak integrated area to the $\mathrm{NO}_{x}$ sensor peak integrated area was calculated. The calculated ratio is tabulated (Table 1) for PETN, TNT, acetonitrile, and methanol. Acetonitrile and methanol were used as controls. Table 1 presents a potential discrimination mechanism with explosives and nonexplosives listed left to right in the order of increasing carbon-to$\mathrm{NO}_{x}$ ratio. The chemical formula for each analyte has been highlighted so as to quantify the number and nature of the nitro groups. It can be inferred from Table 1 that the ratio of peak area measured by the $\mathrm{HC}$ sensor to the peak area measured by the total $\mathrm{NO}_{x}$ sensor is unique for each analyte. 
TABLE 1: Potential discrimination mechanism for explosives.

\begin{tabular}{lcccc}
\hline Analyte & PETN & TNT & Acetonitrile & Methanol \\
\hline Chemical formula & $\mathrm{C}_{5} \mathrm{H}_{8}\left(\mathrm{NO}_{2}\right)_{4} \mathrm{O}_{4}$ & $\mathrm{C}_{7} \mathrm{H}_{5}\left(\mathrm{NO}_{2}\right)_{3}$ & $\mathrm{C}_{2} \mathrm{H}_{3} \mathrm{~N}$ & $\mathrm{CH}_{3} \mathrm{OH}$ \\
$\mathrm{C} / \mathrm{NO}_{x}$ ratio & 1.25 & 2.33 & $\infty$ & $\infty$ \\
$\mathrm{HC} \mathrm{NO}_{x}$ ratio range & $1.7-2.7$ & $14-30$ & $250-275$ & 10,000 \\
\hline
\end{tabular}

TABLE 2: Comparison of detection limit and sensitivity: previous work versus current work.

\begin{tabular}{lcccccc}
\hline $\begin{array}{l}\text { HC sensor } \\
\text { sensitivity } \\
(\mathrm{V} \cdot \mathrm{s})\end{array}$ & $\begin{array}{c}\text { Baseline } \\
(\mathrm{V} \cdot \mathrm{s})\end{array}$ & $\begin{array}{c}200 \mathrm{ng} \\
(\mathrm{V} \cdot \mathrm{s})\end{array}$ & $\begin{array}{c}1 \mu \mathrm{g} \\
(\mathrm{V} \cdot \mathrm{s})\end{array}$ & $\begin{array}{c}2 \mu \mathrm{g} \\
(\mathrm{V} \cdot \mathrm{s})\end{array}$ & $\begin{array}{c}3 \mu \mathrm{g} \\
(\mathrm{V} \cdot \mathrm{s})\end{array}$ & $\begin{array}{c}10 \mu \mathrm{g} \\
(\mathrm{V} \cdot \mathrm{s})\end{array}$ \\
\hline $\begin{array}{l}\text { Previous work } \\
\text { Current work }\end{array}$ & 0.15 & 0.155 & 0.332 & 0.347 & 0.441 & 0.765 \\
\hline
\end{tabular}

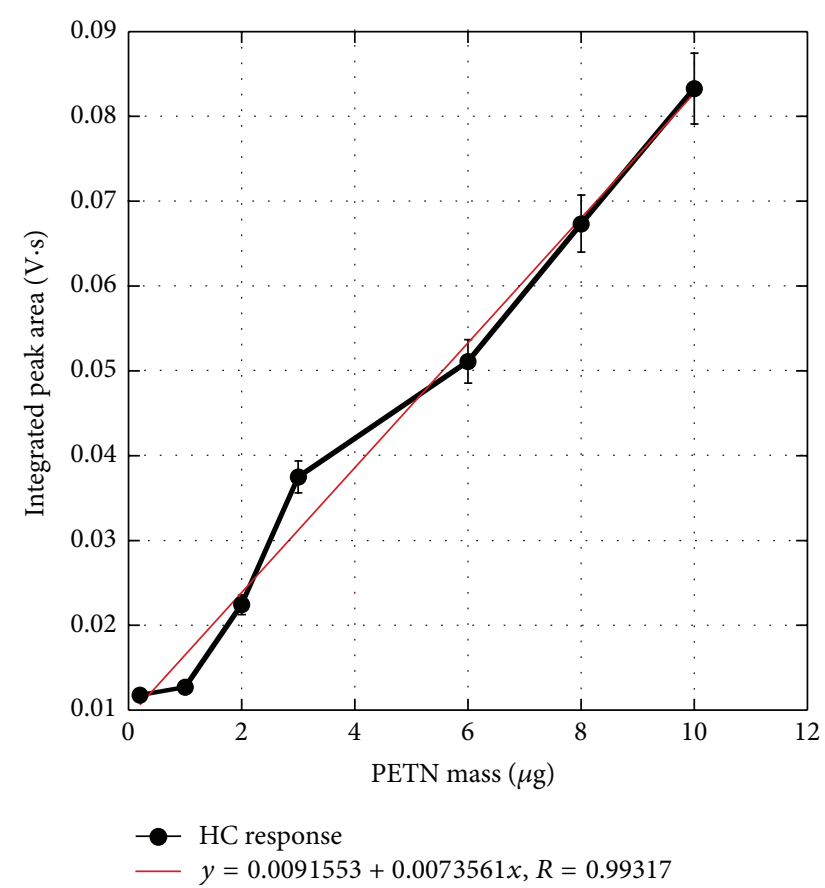

FIGURE 5: Integrated peak area of HC sensor as a function of PETN concentration. The error bars are shown in the graph.

Such a scheme has the potential to discriminate between the explosives and nonexplosives once the gas phase chemistry is understood and the sensor setup is optimized to linearize the sensor response with respect to analyte concentration. The fact that a unique ratio of $\mathrm{HC} / \mathrm{NO}_{x}$ is obtained for each species identifies a method of discriminating high explosives using electrochemical potentiometric gas sensors.

When compared with the externally heated tape-cast sensors, the investigated stick sensor with integrated heater had a lower detection limit of $200 \mathrm{ng}$ as opposed to $1 \mu \mathrm{g}$ (shown in Table 2). However, the sensitivity levels were found to be lower in the new sensor configuration due to large catalytic surface area. Future work includes building a new detector enclosure sensor packaging to permit the use of a dedicated pair of sticks sensors (one optimized for $\mathrm{NO}_{x}$ and one optimized for $\mathrm{HC}$ response) with minimal

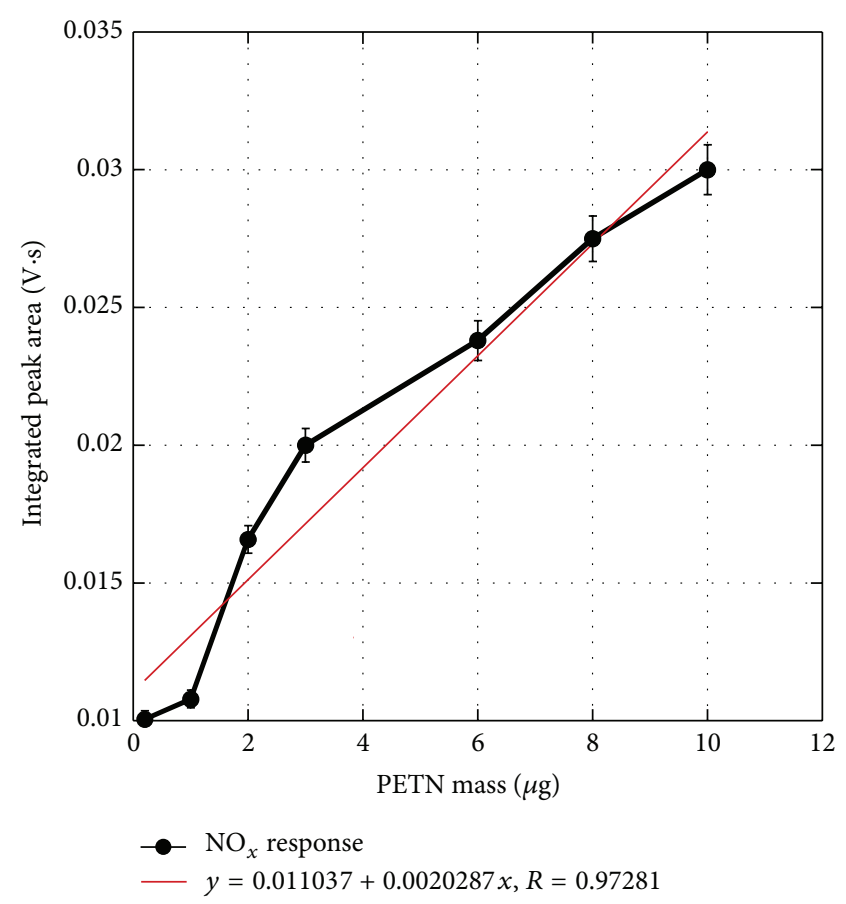

FIgURE 6: Integrated peak area of $\mathrm{NO}_{x}$ sensor as a function of PETN concentration. The error bars are shown in the graph.

triple phase boundary. The $\mathrm{NO}_{x}$ and $\mathrm{HC}$ responses to an HE sample will be recorded simultaneously rather than in separate experiments. This platform will incorporate its own independent heater. We will screen explosives with similar chemical formulation such as TNT and DNT and evaluate the $\mathrm{HC} / \mathrm{NO}_{x}$ ratio for different explosives to see if this electrochemical fingerprinting approach is a robust method for discrimination.

\section{Conclusions}

The paper reports on the detection of PETN using electrochemical gas sensor. Based on the mixed potential sensing mechanism, a single precommercial prototype preferential $\mathrm{HC}$ and $\mathrm{NO}_{x}$ sensor was used to screen various 
concentrations of PETN. Quantitative measurements based on hydrocarbon and nitrogen oxide sensor responses indicated that the detector sensitivity scaled proportionally with the mass of the explosives (down to $200 \mathrm{ng}$ ). The ratio of the $\mathrm{HC}$ sensor peak to the $\mathrm{NO}_{x}$ sensor peak seems to impart the selectivity needed in field conditions. In summary, the ability to use multiple electrochemical gas sensors tuned to distinct threat chemistries (e.g., compounds containing one of the breakdown combinations of $\mathrm{C}, \mathrm{H}, \mathrm{N}$, and $\mathrm{O}$ ) might permit the construction of detector systems to screen a diverse palette of threats with lower rates of false positives and negatives. Future work will focus on building a dedicated multisensor platform and optimizing that platform for improved sensitivity and discrimination ability.

\section{Conflict of Interests}

The authors declare that there is no conflict of interests regarding the publication of this paper.

\section{Acknowledgments}

The authors would like to acknowledge the WSU Vancouver internal grant and WSU seed grant for successful completion of the work.

\section{References}

[1] U.S. Department of Homeland Security: Implementing 9/11 Commission Recommendations, 2011, http://www.dhs.gov/xlibrary/assets/implementing-9-11-commission-report-progress2011.pdf.

[2] T. L. Andrew and T. M. Swager, "A fluorescence turn-on mechanism to detect high explosives RDX and PETN," Journal of the American Chemical Society, vol. 129, no. 23, pp. 7254-7255, 2007.

[3] E. M. A. Ali, H. G. M. Edwards, and I. J. Scowen, "Raman spectroscopy and security applications: the detection of explosives and precursors on clothing," Journal of Raman Spectroscopy, vol. 40, no. 12, pp. 2009-2014, 2009.

[4] R. G. Ewing, B. H. Clowers, and D. A. Atkinson, "Direct realtime detection of vapors from explosive compounds," Analytical Chemistry, vol. 85, no. 22, pp. 10977-10983, 2013.

[5] M. Tabrizchi and V. ILbeigi, "Detection of explosives by positive corona discharge ion mobility spectrometry," Journal of Hazardous Materials, vol. 176, no. 1-3, pp. 692-696, 2010.

[6] M. Boehme, F. Voelklein, and W. Ensinger, "Low cost chemical sensor device for supersensitive pentaerythritol tetranitrate (PETN) explosives detection based on titanium dioxide nanotubes," Sensors and Actuators B, vol. 158, no. 1, pp. 286-291, 2011.

[7] K. Brudzewski, S. Osowski, and W. Pawlowski, "Metal oxide sensor arrays for detection of explosives at sub-parts-per million concentration levels by the differential electronic nose," Sensors and Actuators, B: Chemical, vol. 161, no. 1, pp. 528-533, 2012.

[8] E. Piccin, N. Dossi, A. Cagan, E. Carrilho, and J. Wang, "Rapid and sensitive measurements of nitrate ester explosives using microchip electrophoresis with electrochemical detection," Analyst, vol. 134, no. 3, pp. 528-532, 2009.
[9] W. M. A. Niessen, Ed., Current Practice of Gas ChromatographyMass Spectrometry, vol. 86 of Chromatographic Science Series, Marcel Dekker, New York, NY, USA, 2001.

[10] S. Castillo, I. Mattila, J. Miettinen, M. Oresic, and T. Hyotylainen, "Data analysis tool for comprehensive two-dimensional gas chromatography/time-of-flight mass spectrometry," Analytical Chemistry, vol. 83, no. 8, pp. 3058-3067, 2011.

[11] J. R. Windmiller and J. Wang, "Wearable electrochemical sensors and biosensors: a review," Electroanalysis, vol. 25, no. 1, pp. 29-46, 2013.

[12] B. J. Privett, J. H. Shin, and M. H. Schoenfisch, "Electrochemical sensors," Analytical Chemistry, vol. 82, no. 12, pp. 4723-4741, 2010.

[13] N. Thiyagarajan, J.-L. Chang, K. Senthilkumar, and J.-M. Zen, "Disposable electrochemical sensors: a mini review," Electrochemistry Communications, vol. 38, pp. 86-90, 2014.

[14] J. C. Oxley, J. L. Smith, and H. Chen, "Decomposition of a multi-peroxidic compound: triacetone triperoxide (TATP), Propellants, Explosives," Pyrotechnics, vol. 27, pp. 209-216, 2002.

[15] D. Schönauer, K. Wiesner, M. Fleischer, and R. Moos, "Selective mixed potential ammonia exhaust gas sensor," Sensors and Actuators, B: Chemical, vol. 140, no. 2, pp. 585-590, 2009.

[16] N. Miura, G. Lu, and N. Yamazoe, "Progress in mixed-potential type devices based on solid electrolyte for sensing redox gases," Solid State Ionics, vol. 136-137, pp. 533-542, 2000.

[17] J. W. Fergus, "Sensing mechanism of non-equilibrium solidelectrolyte-based chemical sensors," Journal of Solid State Electrochemistry, vol. 15, no. 5, pp. 971-984, 2011.

[18] P. K. Sekhar, E. L. Brosha, R. Mukundan, K. L. Linker, C. Brusseau, and F. H. Garzon, "Trace detection and discrimination of explosives using electrochemical potentiometric gas sensors," Journal of Hazardous Materials, vol. 190, no. 1-3, pp. 125-132, 2011.

[19] K. L. Linker, F. J. Conrad, C. A. Custer, and C. L. Rhykerd, "Particle Preconcentrator," US Patent 5854431, 1998.

[20] P. K. Sekhar, E. L. Brosha, R. Mukundan et al., "Application of commercial automotive sensor manufacturing methods for $\mathrm{NOx} / \mathrm{NH} 3$ mixed potential sensors for on-board emissions control," Sensors and Actuators, B: Chemical, vol. 144, no. 1, pp. 112-119, 2010.

[21] R. Mukundan, K. Teranishi, E. L. Brosha, and F. H. Garzon, "Nitrogen oxide sensors based on Yttria-stabilized zirconia electrolyte and oxide electrodes," Electrochemical and SolidState Letters, vol. 10, no. 2, pp. J26-J29, 2007.

[22] K. L. Linker, F. A. Bouchier, D. W. Hannum, and C. L. Rhykerd, "Human portable preconcentrator system," US Patent \#6523393, 2003.

[23] C. M. Tarver, T. D. Tran, and R. E. Whipple, “Thermal decomposition of pentaerythritol tetranitrate," Propellants, Explosives, Pyrotechnics, vol. 28, no. 4, pp. 189-193, 2003. 

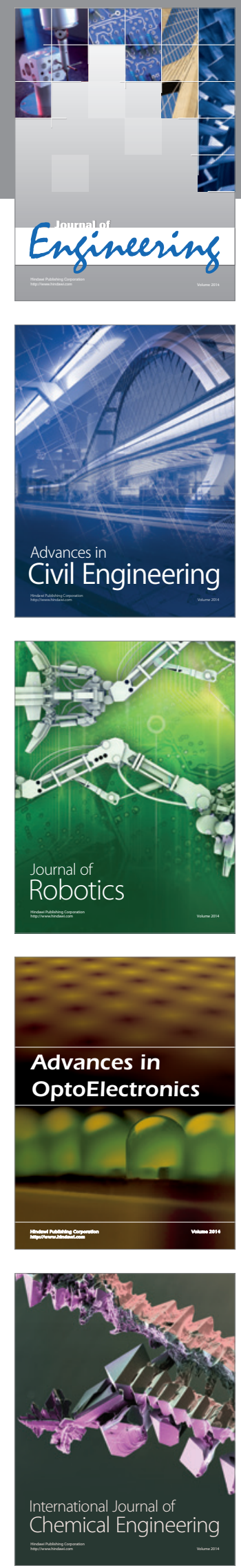

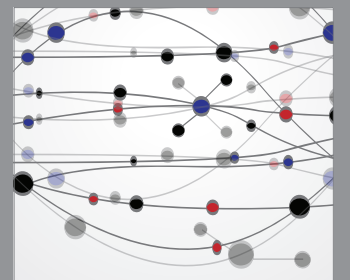

The Scientific World Journal
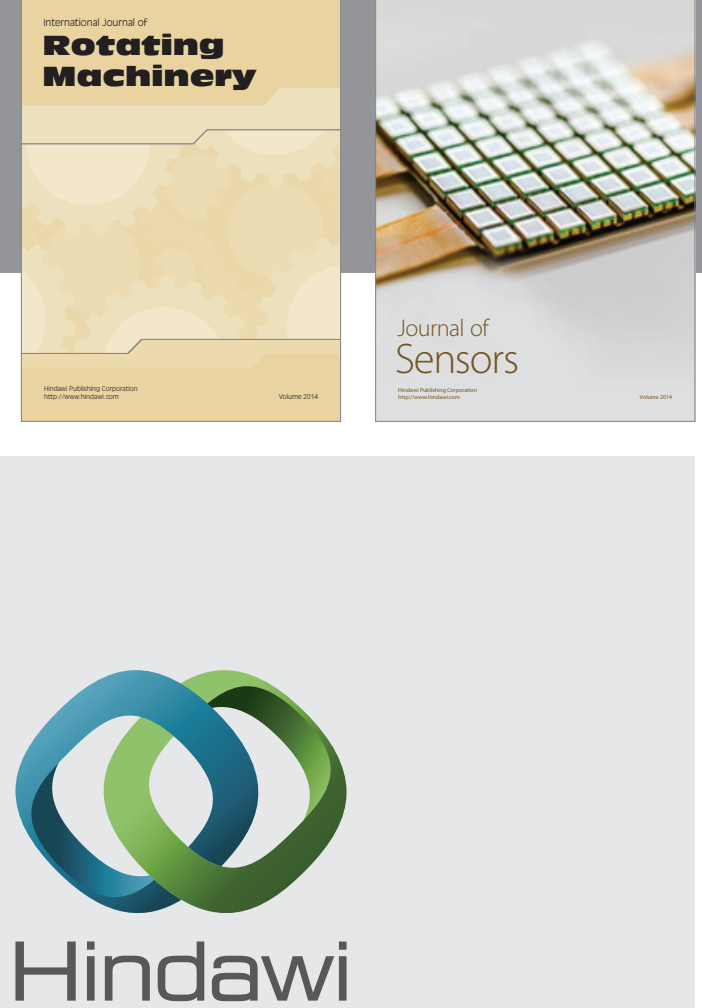

Submit your manuscripts at http://www.hindawi.com
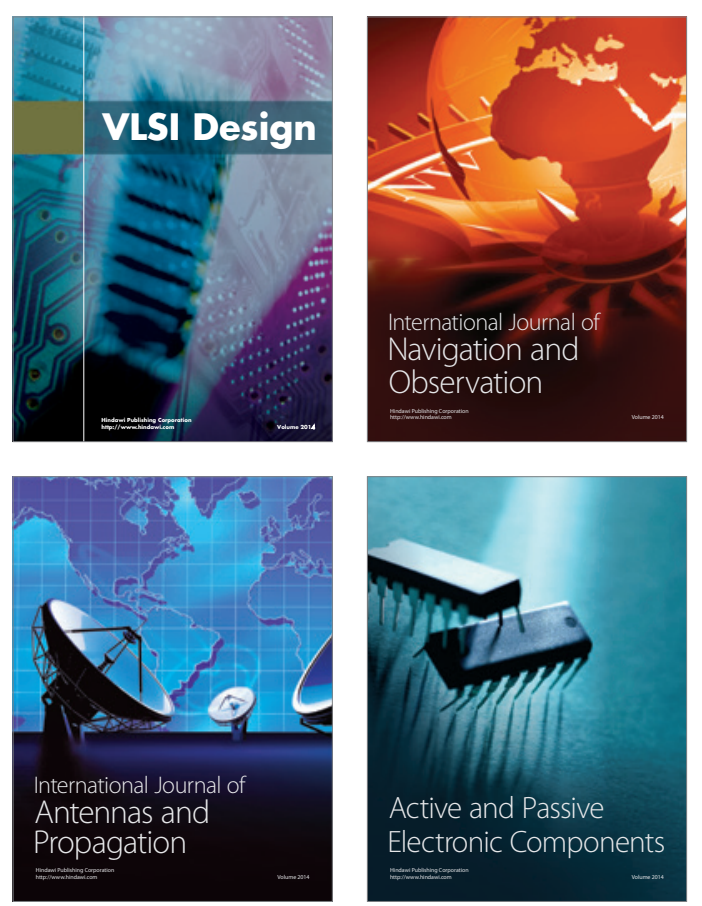
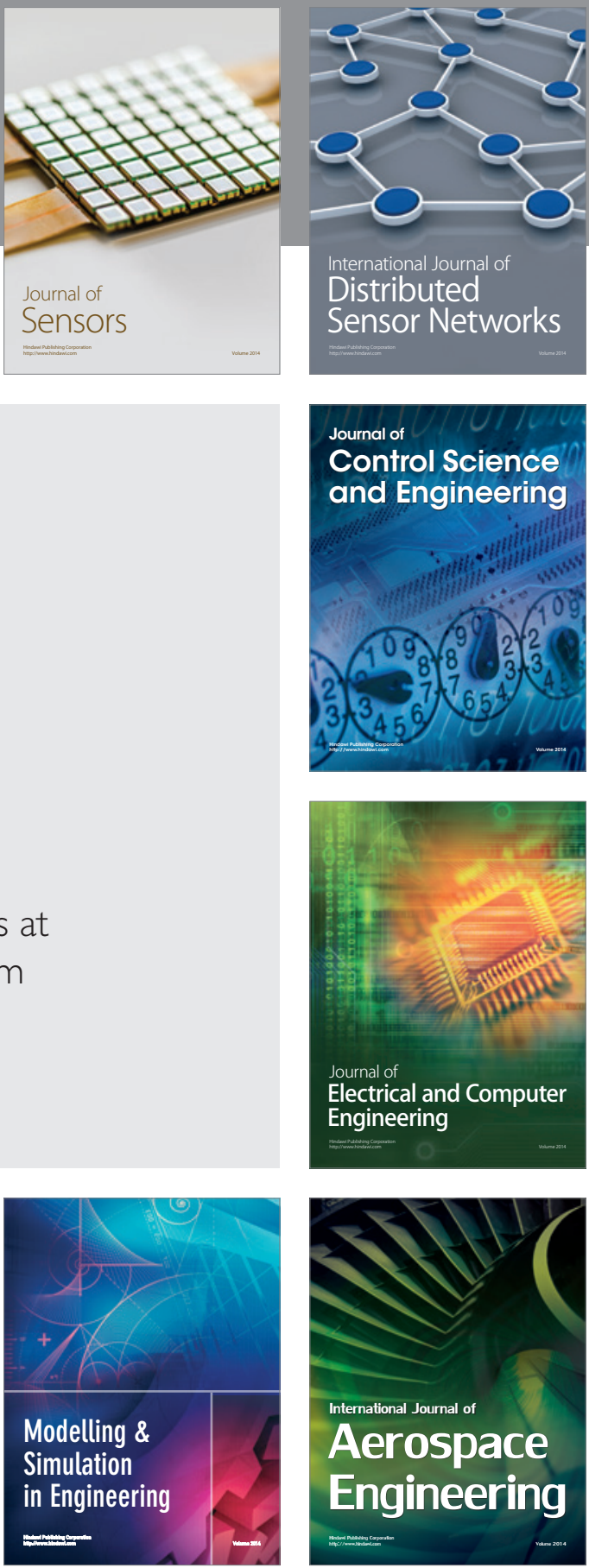

Journal of

Control Science

and Engineering
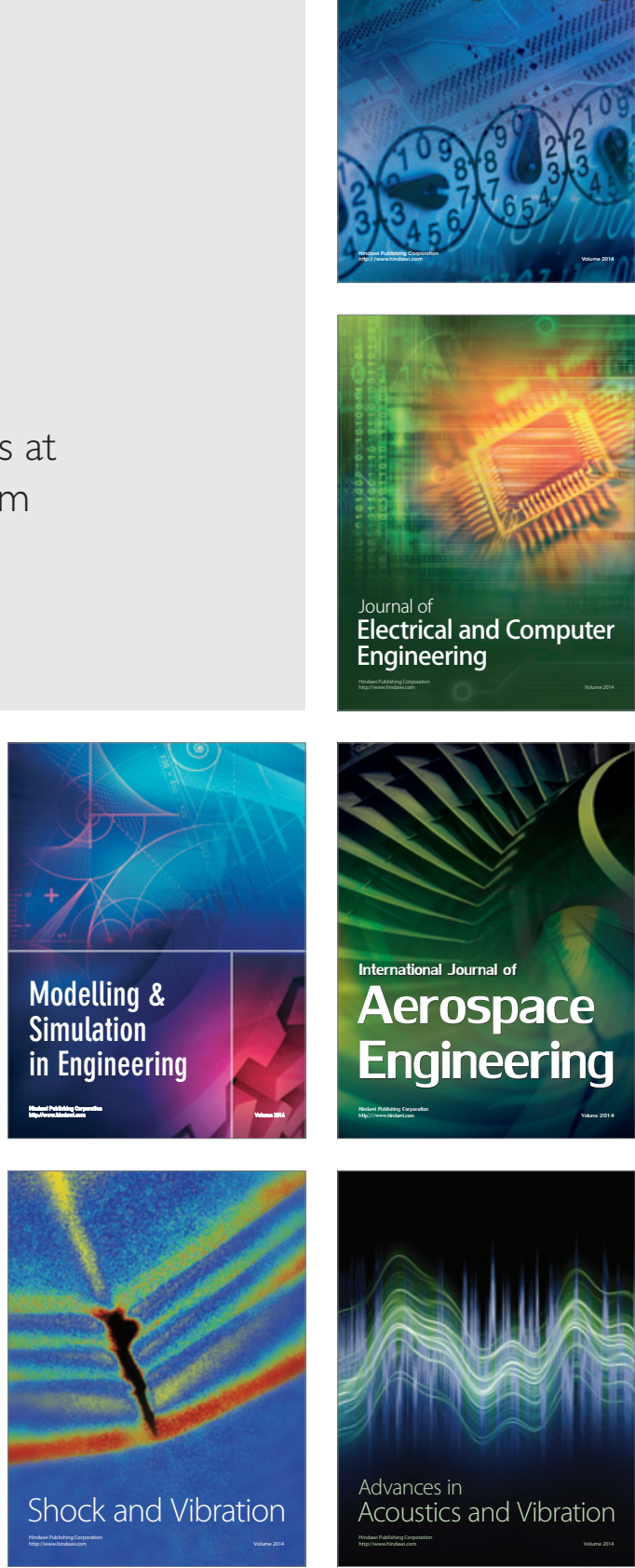